ISSN 1927-9434

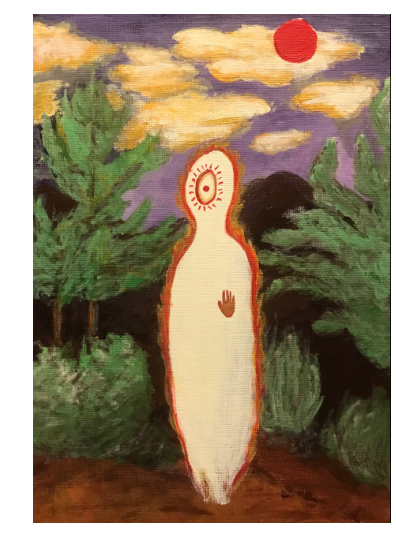

\title{
Engaging the Social: Community Engaged Pedagogy in the Context of Decolonization and Transformation at the University of Cape Town ${ }^{1}$
}

Chihota, Justice

Stellenbosch University, South Africa

justicechihota@sun.ac.za

Louskieter, Lance

University of Cape Town, South Africa

LSKLAN001@myuct.ac.za

Mkhonta, Sizwe

Management Consultant with Africa

International Advisors

sizwe.mkhonta@alumni.uct.ac.za
Harding, Genevieve

Boston Consulting Group

genevieve@rkng.co.za

McMillan, Janice ${ }^{2}$

University of Cape Town

$\underline{\text { Janice.mcmillan@uct.ac.za }}$

Oliver, Sarah

United Religions Initiative

sarah.cc.oliver@gmail.com

Received: October 13, 2020. Revised: July 5, 2021. Accepted: July 16, 2021. Published: October 18, 2021

How to cite this text: Chihota, J., Harding, G., Louskieter, L., McMillan, J., Mkhonta, S., Oliver, S. (2021).

Engaging the social: Community engaged pedagogy in the context of decolonization and transformation at the University of Cape Town. International Journal of Engineering, Social Justice and Peace, 8(2), pages 72-85.

Globally, higher education is at a crossroads on so many levels: funding, course development, who our students are, what knowledge is relevant for the world of work and beyond, what kinds of students do we want to graduate, and who are we as educators. All these questions (and more)

\footnotetext{
${ }^{1}$ We would like to acknowledge the National Research Foundation (NRF) whose funding of a community engagement grant at the University of Cape Town made the writing of this paper possible. Project PI Prof Ulrike Rivett was very supportive of our work.

${ }^{2}$ Corresponding author.
} 
have been around for some time; the current COVID-19 context however brings them even more sharply to the fore.

This paper responds to the prompt about how we train professionals for the future so that they do not participate in systems of oppression and inequality. It was written in 2017 in response to a conference on social and epistemic justice in the wake of the 2015 student protest movements and was written collaboratively by an intergenerational group of educators working on a course in the Engineering and Built Environment (EBE) Faculty at the University of Cape Town, South Africa $^{3}$. All of us have a strong commitment to social justice, and to providing engineering students with an opportunity to think about their professional identity through the lens of community engagement. While written before the onset of COVID-19, we believe that the arguments we make are pertinent to the current context. Drawing on the Honors' thesis of one member of our group ${ }^{4}$, we sought to reflect on and analyze our work in this context. In particular, the principles of multi-centricity, indigeneity and reflexivity (Dei, 2014) proved useful in making sense of our practice and our work together.

\section{Key Words:}

Social Justice; Decolonisation; Intentionality; Multicentricity; Indigeneity; Reflexivity.

\footnotetext{
${ }^{3}$ It was presented to the "Community engagement: towards epistemic and social justice" conference, hosted jointly by Durban University of Technology and Rhodes University, Durban 31 May - 2 June 2017.

${ }^{4}$ See Oliver (2015) in the references.
} 
Justice Chihota completed the B.Sc., M.Sc., and Ph.D. degrees in Electrical Engineering from the University of Cape Town (South Africa) in 2014, 2015, and 2018. During the final year of his undergraduate studies in 2014, Justice took the Social Infrastructures (SI) course as an elective. Inspired by the transformative power within the pedagogical approaches, Justice joined the SI teaching team as a tutor in 2016 and later assumed the role of lecturer in 2018. From 2019 to 2020, he served as a Research Engineer with the Centre for Renewable and Sustainable Energy Studies (CRSES), Stellenbosch, South Africa. Since 2020, he has been a Post-doctoral Fellow with the Electrical and Electronic Engineering Department at Stellenbosch University. His research interests include distribution network planning, load modelling, renewable energy grid integration, and autonomous control of inverter-based energy resources.

ORCID: https://orcid.org/0000-0001-9716-4674; justicechihota@sun.ac.za

Genevieve Harding graduated from UCT with a BSc in Chemical Engineering (2015), and MSc in Chemical Engineering (2018). During the $2^{\text {nd }}$ year of her undergraduate degree she was a student on the Social Infrastructures course. The experience was transformative and placed her whole degree in a context of how engineering assets and skills can be leveraged in "real life". Genevieve later part-took in the course as a tutor (2015) and finally as a member of the teaching team (2016-2018). Genevieve found the relational aspects of teaching Social Infrastructure, both with the teaching team and with the students, to be a welcome counter-balance to the sometimes lonely journey of her masters. Genevieve is currently working as a consultant at Boston Consulting Group (BCG).

Lance Louskieter is a health systems and policy researcher, and a queer and decolonial scholar and activist. They are currently a PhD candidate and senior Atlantic Fellow for Health Equity. Lance was named an Emerging Voice in Global Health in 2020. Their PhD explores health systems responsiveness to queer users in primary health care settings. Lance's advocacy and activism includes partnering with Sex Workers Education and Advocacy Task Force (SWEAT) and they serve as a board member of the Sexual and Reproductive Justice Coalition (SRJC) where they champion rights and access to health for sex workers, queer people, and other marginalised populations by contributing to policy and implementation processes. Lance worked with the Global Citizenship Programme as a researcher and facilitator and also convened the Social Infrastructure (SI) course in 2018. Lance currently uses creative participatory and popular education methodologies and pedagogies to facilitate local, national, and global advocacy spaces to enable transformative approaches to achieve health equity.@lancelouskieter https://orcid.org/0000-0003-2289-1302

Janice McMillan is an Associate Professor based in the Centre for Innovation in Learning and Teaching (CILT) in the Centre for Higher Education Development (CHED) at the University of Cape Town and was convenor and designer of the Social Infrastructures course from its 
inception in 2013 until 2019. Janice is a member of several university and faculty committees and since mid-2017, Janice has a role at the institutional level giving direction to engaged scholarship and social responsiveness. Janice is also a collaborator on several global partnerships linked to developing new and authentic forms of engagement across universitycommunity boundaries. Janice completed her PhD in Sociology at UCT in 2008, focussing on service learning as a form of boundary work in higher education. She has received several awards for her teaching, including a Distinguished Teacher Award, the highest teaching award at UCT. Janice's teaching, research and development interests include deliberation as a pedagogical tool; community-engaged learning; university-community partnerships more broadly, and faculty and institutional development.

Sizwe Mkhonta is a UCT MSc. Eng in Electrical Engineering Graduate, with research experience in the impact of Geomagnetically Induced Currents on transformers. This has afforded him the opportunity to author and contribute towards several publications around the response of transformers towards extreme GICs introduced by Geomagnetic storms. Sizwe is currently working as a Management Consultant with Africa International Advisors. His work is centered around energy and public sector projects within South Africa and the broader SADC. Sizwe carries a passion for the impact of energy within our society. The future of energy looks very different globally, with the shift towards renewable sources. According to Sizwe, within developing economies like South Africa, the issue of a just transition becomes a critical aspect to consider as the future of energy is envisioned. This will require a consideration of socioeconomic dynamics, acting as an enabler for the technical transition.

Sarah Oliver graduated from UCT in 2015 with a first class Honours Degree in Social Anthropology. Sarah's thesis focused on community engagement in curricula of higher education as a way of contributing to decolonisation and transformation. This led her to join the UCT Global Citizenship Programme, as the Social Infrastructures Course became the ideal case study for her research. From 2016 through to 2019, Sarah worked with the Global Citizenship Programme as a Facilitator and Assistant Lecturer working on courses such as 'GC2: Service, Citizenship and Social Justice', and 'GC4: Dialogue and Deliberation for Active Citizenship'. Sarah now serves as the Associate Director of Global Programmes for the United Religions Initiative (URI), a global interfaith peacebuilding organisation which aims to support and connect grassroots community initiatives working for peace, justice and healing in our world. 


\section{INTRODUCTION AND BACKGROUND CONTEXT}

Community engaged pedagogy, as a teaching practice in higher education, while innovative, is not inherently transformative. Particularly in the current context of higher education, with the calls for 'transformation' and 'decolonisation', community engagement or community engaged learning does not inherently contribute to social justice. However, as an interdisciplinary teaching team, based at the University of Cape Town (UCT), we would like to offer our reflections on our practice of community engaged learning as a possible start to understanding how community engaged learning can contribute to conversations of decolonisation and transformation. We are aware that no pedagogy or curriculum is inherently transformative. It is hoped that the paper will show how through framing our teaching with concepts such as those in Dei's work, we can graduate engineering professionals with a commitment to social justice.

Our case study is the Social Infrastructures course, a humanities elective course for engineering students that runs in partnership between the Department of Professional Communications Studies in the Engineering and Built Environment (EBE) Faculty, and the Centre for Higher Education Development (CHED), drawing on content from the UCT global citizenship programme . Based on student feedback and the fact that the course runs full (with a waiting list) each year, it appears that by intentionally engaging the social in the multiple levels of community-engaged teaching practice, the spaces we are creating through the Social Infrastructures course have enabled several key characteristics of transformative practice. These include:

- disrupting the traditional knowledge hierarchies of academia both in the relationships in the teaching team and in the relationships with community partners;

- valuing student lived experiences;

- introducing popular education epistemologies in teaching spaces;

- encouraging students to reflect on their identities not just as students, but as active citizens and emerging professionals as well;

- to help students understand that no disciplines are neutral, and are in fact often very strongly framed.

In terms of the disciplines and their impact on teaching and learning, Boud and Walker (1998:200) put it thus:

Disciplines and professions define what counts as legitimate knowledge and acceptable practice by their members. The invisibility of this framing offers a major challenge for teachers in working with students, as staff are normally enculturated into their discipline or profession and take it for granted. 
One of the papers we draw on in the Social Infrastructures course that speaks to this issue in very concrete ways is that of Banks and Lachney (2017). The authors talk about the nonneutrality and even the 'violence' of engineering knowledge in particular contexts and sets of power relations. They argue therefore that it is important for engineering educators to

...leverage the understanding of human safety, property, and violence by those in environmental and racial justice movements to help engineering students better understand their role as political actors (Banks \& Lachney, 2017: 2)

By so doing the authors argue, engineering professionals would be in a better position to 'find alternative, non-violent solutions to design problems' (ibid: 2017:5).

The notion of putting pressure on the disciplines as we have discussed above aligns to some of the key aspects that George Dei (2014) refers to as the starting point of decolonising the African curriculum. Dei's concepts of multicentricity, indigeneity and reflexivity have been useful for us in reflecting on how our practice of community engaged learning can offer a positive contribution to the conversation of reaching social justice in higher education.

\section{Decolonisation in Higher Education}

This paper draws on the thesis work of one of our team members, where Dei's argument of the three central tenets needed for decolonising the African curriculum - multicentricity, indigeneity and reflexivity - were mirrored against the experiences of students on the Social Infrastructures course (Oliver, 2015). We are profoundly aware that 'decolonisation' is a contested term, and in no way is it something we inherently claim in our work. However, the framework provided by Dei as well as the growing discourse of decolonisation in higher education has been helpful in understanding how we are making sense of our work, and it is this that we hope to reflect on in this paper. Particularly as a diverse team with a commitment to reflective critical practice, our 'intergenerational' and 'cross contextual' conversations have raised powerful and disruptive questions: (1) how might our teaching and learning practice help students engage and navigate the 'social'?, (2) what role does community engaged learning play in this?, and (3) how at all does this intersect with calls for decolonisation?

The calls for decolonisation and transformation are not new to South African academic institutions, but have received a new energy with the 2015 student-led movements of \#RhodesMustFall and \#FeesMustFall. ${ }^{5}$ The footnote provides links to further explanation of these protests but in essence the \#RMF protests were about the colonial university, including its curriculum, and the alienation experienced by (particularly) black students on campus. There was

\footnotetext{
${ }^{5}$ There are many references to this protest movement. For an overview this might be a helpful start https://en.wikipedia.org/wiki/Rhodes Must Fall; see also See https://www.theguardian.com/uknews/2016/mar/16/the-real-meaning-of-rhodes-must-fall https:/www.globalcitizen.org/en/content/rhodes-must-fallfounder-racist-statues/. See referecnes for further sources .
} 
pressure on the university leadership for fundamental curriculum reform. The movement itself, which grew into a national movement, was started at UCT and symbolised by the demand for the removal of the Cecil John Rhodes statue that stood in a prominent place on campus. Rhodes was a colonial land- and slave-owner and bequeathed the land on which the university stands today. The statue was finally removed. The protests reflect the critique of the eurocentric/colonial institutional culture that still informs the content, the teaching, and the pedagogy that students experience. Particularly for engineering students, there is a need to locate and make relevant the technical knowledge of engineering to a/our particular social context, as well as value student voices and experiences in the classroom space as important parts of the decolonial project. There is a need to acknowledge the social. The \#FMF protests built on the \#RMF protests and took them to the national Department of Higher Education ${ }^{6}$ demanding free higher education. This demand was not met but there was a substantial shift in fee structures.

Returning to the issue of a decolonised curriculum, Dei argues for the need to remake our institutions, through practical strategies of Africanizing the curriculum with three central tenets: 1) Multicentricity, 2) Indigeneity, and 3) Reflexivity (Dei, 2014:176). The first tenet is to integrate different knowledges, creating a multi-centric learning space that breaks down existing knowledge hierarchies (Dei, 2014:177). The second step revolves around the notion of 'indigeneity' in the sense of recognising student identities and life experiences as valid and integral to the learning process. Dei writes that "African indigenous knowledges speak to a local cultural resource knowledge base expressive of ideas, norms, cultural knowledges and philosophies possessed by local people/communities concerning realities of everyday living and survival" (Dei, 2014:167). Therefore, indigenous knowledge in the sense of local experiences of place and space, is crucial to reframing the 'African' university. The third central tenet used by Dei is reflexivity. By this it is understood that there is value placed on students' ability to reflect on their learning, recognising the connections between knowledge, self and context.

\section{THE SOCIAL INFRASTRUCTURES COURSE}

The Social Infrastructures course is a credit-bearing course offered to students in the EBE faculty, as a humanities elective. The aim of the course is to provide a framework to assist engineering students navigate the broader social context into which they will bring their knowledge, skills and values as professionals. In particular, we are interested in working with students to understand issues of social justice that are important in our context of extreme inequality in South Africa. The pedagogical approach in the course combines classroom-based learning and reflection with community-engagement taking the form of different off-campus classes created in partnership with various Community Based Organisations (CBOs).

The course runs during the Winter and/or Summer terms, over an intensive four- or five-week period, and is structured in two parts. The first part considers concepts to frame thinking around community engagement and the second part looks at different infrastructural themes, such as

\footnotetext{
${ }^{6}$ The department oversees and susidises the higher education system in South Africa
} 
water, housing and sanitation, in the context of local communities. In groups, students visit a particular community activist connected to a particular issue. These partnerships are mostly formed through a growing relationship with the Development Action Group (DAG). As a form of assessment, students write two reflective essays (also posted as blogs) and submit a final exam paper written in two parts (a conceptual essay and a learning review essay). The class is a combination of students from within the EBE faculty mixed across years of study and engineering discipline (electrical, mechanical, chemical, etc.). The teaching team is also mixed across disciplines with social scientists teaching with engineers.

We have identified the three different spaces from which to expand upon and provide examples of our experiences of Dei's three tenets of multicentricity, indigeneity and reflexivity: the classroom sessions, the off-campus classes with community partners, and the teaching team collaboration.

\section{1) Multicentricity}

Knowledge is an important concept in the Social Infrastructures course, in all aspects of the teaching and learning process. From the way the content is framed, the kinds of knowledge brought into the classroom, and how the content is taught, the aim is on valuing different forms of knowledge, disrupting knowledge hierarchies between university institutions, students and 'communities' and embarking on a process of knowledge co-creation. Universities continue to exist as gatekeepers of 'specialized knowledge.' Because of this, Pillay (2015: np) argues the university is "at the heart of epistemic violence. It is where authorized and legitimate knowledge is cultivated, preserved and protected." If we hope to achieve justice within higher education, then a considerably different approach to knowledge is needed. In order to disrupt this authority and move towards a 'pluriversity' instead of a 'university' (Nyamnjoh, 2012:131), Dei uses the helpful concept of 'multi-centricity' as the first step in moving towards a decolonized education system in Africa. By this, he means taking a multi-centric or polycentric approach to the curriculum in acknowledging and cultivating multiple ways of knowing (Dei, 2014:171).

In the Social Infrastructures course, this plays out in very particular ways. The classroom space, to begin with, is designed to value knowledge beyond the boundaries of university knowledge. In the classroom, we position students as 'with knowledge,' as opposed to empty vessels. We draw on their knowledge in group work and by 'buzzing' about a topic, encouraging engagement across different lived experiences.

As an example, during the third session of the course, we explored the notion/theme of "Knowledge". We asked questions such as: What is knowledge? Where does it come from? Who has it? Who doesn't? What is it for? The main activity of this session was to build knowledge trees, which were developed by identifying different sources of knowledge and their collective learnings from each source. As part of the activity, students were asked to consider what was learnt from one's family, from school, from nature, and from experience. This framed the students' lived experiences as valuable and important in the classroom. The knowledge trees 
were displayed on the walls of the classroom, and a 'gallery walk' followed the activity. The gallery walk illustrated that there is a lot that we can learn from everyone in the room. This activity and exercise demonstrated that it is necessary to value multiple sources of knowledge, and began to position the teaching and learning of the off-campus classes as important.

Students go on two off-campus classes during the course. The first is to the District Six museum in the city which marks the history and trauma of Apartheid forced removals in an area known as Distract $\mathrm{Six}^{7}$. For the second off-campus class, students (in groups of 10) spend a day with one $\mathrm{CBO}$, where the members of the $\mathrm{CBO}$ are positioned as educators for the day. In the off-campus classes, we ask members of various CBOs to share their story (as they would like to tell it), while speaking to five themes (History of the organisation; history of the area; contested issues, strategies and tactics; knowledge; and networks and partnerships). The students are encouraged to engage with their $\mathrm{CBO}$ members, ask questions, and listen openly. The following day, the students regroup and are themselves positioned as educators, asked to teach their peers about the $\mathrm{CBO}$ they visited. This disrupts traditional teaching spaces, not only in terms of location, but also in terms of who can teach and what knowledge is valued where.

Finally in terms of how we see multicentricity in the teaching team itself; the language of 'teaching team' demonstrates that a collection of voices and experiences is valued in the teaching and learning space. Furthermore, the team is multidisciplinary and intergenerational. The team is a collection of engineers, social scientists, a fine art student, and others; each bringing (and disrupting) our respective discipline-based knowledge. The team is a mix of undergraduates, postgraduates and staff, which disrupts the idea of 'who is allowed to teach'. The team also is mixed in terms of race and gender. This models in the classroom the collaboration that is required to work across contexts, and arguably the multitude of knowledge(s) that is required to be an active citizen. Community engaged learning as a practice therefore helps students 'navigate the social' by breaking down knowledge hierarchies, and engaging with the knowledge of real life lived experience, valuing the horizontal learning experience between student to student, student to community partner, and student to facilitator.

\section{2) Indigeneity}

The second central tenet that Dei offers is that of 'indigeneity'. 'Indigeneity' positions students as active knowers and contextualises education to the land and the life experiences of the students (Dei, 2014:171). It is about bringing student experiences into the classroom, and in doing so, actively recognising the value of popular epistemologies. In terms of the classroom space, Dei argues that 'the starting point and the finishing line of education should be students' immediate life experience and local context' (Dei, 2012:171). Knowledge itself is a product of experience, and we need to bring ourselves more into the experiences of knowledge production. More than anything on a practical level, personal experiences give access to deeper understandings of knowledge. The Knowledge Tree exercise is just one example, but this practice of starting with

\footnotetext{
${ }^{7}$ https://www.districtsix.co.za/
} 
the students' experience, and continually asking them to locate themselves in the teaching and learning process runs throughout the course.

In terms of our work with community partners, the value of indigeneity is inherent to the practice of community-engaged learning. It plays out in all aspects of student engagements with the community partners as we place an emphasis on valuing the knowledge and life experiences of the community partners. A key aspect of our engagement with the CBOs is building what we refer to with our partners as a 'horizontal learning platform' through which we aim to learn together in multiple spaces both in and outside the classroom. An example of this is that we also invite our community partners into our classroom for our session on 'Development' about which they have much to teach our students. The hopes of this collaboration is to bring community knowledge into the classroom, blurring the boundary between the university and 'community.' We had students and $\mathrm{CBO}$ members alike participating in the activities together, and engaging in group discussions. By inviting the CBOs into the classroom, we emphasised the limited value of technical/university knowledge. This knowledge needs to be supplemented by external/ 'community' knowledge to be relevant outside of the university boundaries. The CBO members helped place knowledge in contexts relevant to local $\mathrm{CBO}$ organisations and members, locating the knowledge for the students to a particular land and life experience.

The teaching team also has a role to play in locating the learning to a particular context. As a teaching team we are people engaging through our common humanity first, and our disciplines second. As facilitators of the classroom space, we are encouraged to draw on examples from our daily life, and recognise the contextual nature of knowledge. Moving beyond the boundaries of university knowledge to a particular place, space and lived experience is central to communityengaged learning as a practice, and central to untangling a curriculum in our context from 'the tentacles of Eurocentric knowledge production' (Dei, 2014:166). With this, however, there needs to be a constant awareness of identity politics, power and positionality, which is where the notion of 'reflexivity' is useful in bringing an awareness and intentionality to the practice of community engaged learning.

\section{3) Reflexivity}

Reflexivity is the final tenet, which Dei described as 'the interrogation of the interconnectivity of the self to the external world' (Dei, 2014:172). It is about students reflecting. As an example from the Social Infrastructures course, the assessments in the course ask students to write two reflective blog posts, a conceptual essay and a learning review essay, and in some cases a presentation. The collection of assignments hopes to engage students in their three different identities: as a student, emerging professional and citizen. The notion of intersecting identities disrupts the focus of their core programmes (where they are positioned solely as engineers). Moreover, during the course we ask the students to "park" their professional identity, and adopt the citizen identity strongly. Much of the course activities are framed through the lens of 'active citizenship.' 
This notion of 'active citizenship' comes across very strongly from our CBO partners. There was a significant moment in one of the course cycles, where at the end of the Development session, one CBO member from the Philippi Horticultural Area Food and Farming Campaign addressed the students about being a citizen. He had prepared a set of PowerPoint slides to accompany his input. Asking for someone in the class to read from slides, it took the class by surprise when another older female CBO member from Valhalla Park United Front Civic Association stepped forward to read the slides. This moment connected their work in an act of solidarity, and showed the students the value of locating oneself in partnership and networks for support.

Understanding ourselves beyond the limited identities of student, teacher and community partner, but instead moving to a space of reflexivity in terms of our intersecting identities as citizens, has emerged as an important framing in our practice. Teaching, as a social process, requires educators to engage with the past, and how the past has shaped one's complex identity. It requires us to interrogate 'the context in which learning occurs, how we are all positioned, and what has shaped prior learning' (McMillan, 2017: 163). As a teaching team we are given the space to reflect on our practices, but more importantly our positionality in the teaching and learning space. Through adopting this practice in our teaching, we hope to encourage students to continue 'engaging the social' in considering issues of social justice, in their intersecting identities of student, citizen and future professional.

\section{REFLECTION}

As noted above, the course has proved very popular and is always oversubscribed. It is also often cited as one of the successful examples of a decolonised teaching and learning space by university administrators and leaders too, which is very gratifying. Before concluding the paper, it might be useful to reflect on some of the key successes, but also indicate some of the gaps and to indicate where the course is today.

The intentionality around so many aspects of the classroom practice - both in the on-campus and off-campus classes - was a huge element of the success of the course. The experience and background of the educators also made a difference as an adult education and popular education approach was central to mediating complex new ideas and helping students develop new lenses to engage to world - not just to better understand it in technically complex ways, but in socially complex ways too. The overall course team spent a lot of time together as a group, getting to know each other, identifying strengths and areas of development for each team member. This allowed us to both work on our strengths but also provide opportunities in a very supportive environment, for team members to try out new roles and responsibilities. Arguably, this modeled the kind of learning we wanted to create for the students. Finally, longstanding partnerships with our $\mathrm{CBO}$ partners ensured that their experiences and voices were centred in the off-campus classes in particular, but also where possible in the on-campus classes as well.

The course also offers the possibilities of moving the links between decoloniality and the SI course forward. One example is the engagement with an explicit conscientisation and reflexivity 
of students within structures of power - enabling them to reflect on their own positionality and the positionality of other students and community partners. This includes a recognition of their own limitations (as students located within a university) and the value of community partners. In addition, the relationships between students enable them to recognize the value of their peers beyond normative value constructed within university spaces and disciplines. This is linked to positionality in terms of gender, patriarchy, race. The SI course thus offers an opportunity to deepen engagement with these issues in very intentional ways ${ }^{8}$.

There are of course always limits or perhaps we might say, challenges, in teaching and learning spaces. The intensity of the work to bring the course to the students in the way that we did, implies a huge commitment from the whole team. This is valuable but also raises the question of sustaining such practices over the longer term. The complex context in South Africa - of deep inequality and resilient yet vulnerable community partners - implies the need for agility in thinking about the off-campus spaces. For some years we were not able to access some of our oldest partners due to issues in the community. Participating in the learning with the partner would have placed them (and our students) at potential risk. The issue of language is also a complex one in this context, where several CBO partners spoke little if any English. In some years it gave e.g. Xhosa-speaking students a chance to take a leadership role in the class through translation, but language is so intimately tied to so many other dimensions of one's lived experience that this needs to be taken on board quite seriously. And finally, the university timetabling schedule does not always allow the kind of time periods we need for the kind of immersed learning we wanted to provide students with and so we used the mid-year Winter Term period. However, over the longer term, it would be important to see how the more traditional lecture timetable itself can be adjusted to accommodate new forms of engaged teaching and learning.

\section{CONCLUSION}

We have used the three central tenets provided by Dei, to reflect on our practice and approach to community engaged learning in the classroom space, the off-campus classes, and in the teaching team. This has begun to provide some links in terms of why and how community engaged learning is potentially relevant in the context of decolonisation and transformation. Overall, the ideas of 'engaging the social' through disrupting knowledge hierarchies, valuing student experiences and popular epistemologies, connecting curricula and learning to a particular land and context, and constantly reflecting on one's positionality and experience of self within the world, are critical to developing an intentional practice of community engaged pedagogy.

\footnotetext{
${ }^{8}$ Interestingly, the original course convenor (McMillan) and the current convenor (Dr Benita Moolman) have been asked to lead an institutional curriculum project focused on embedding social responsiveness (UCT's term for community engagement) into the undergraduate curriculum across the university. The SI course is used as the starting point for the overall project, together with a new course also in the EBE faculty that one of the authors (McMillan) has developed over the past 2 years called The Citizen Professional.
} 
Creating deliberate spaces for deep and engaged learning is crucial if higher education is to play a role in contributing to social justice.

All of this is critical in thinking about the education of professionals moving forward. The current COVID-19 context brings some of the issues raised above into stark relief, more than ever before, e.g. overwhelming and enduring inequality; gender-based violence; food security; and good governance to name a few of the critical issues. We believe that through intentional teaching and learning, in particular approaches that ask students to 'engage the social', are critical. As staff teaching in these spaces, we are implicated here too and need to think about how we position our work going forward. The Social Infrastructures course is under new academic leadership in which issues of decoloniality, together with African feminist epistemologies, are strongly visible in the practice. The course also moved into the virtual online space in the COVID context in 2020 in what UCT described as 'emergency remote teaching' to signify that the context was far from ideal. The authors of this paper are not involved in the course anymore and thus it is not possible to give a full account of how the course now looks in the COVID-19 context. However, it is still running with increasing numbers of students attending 9

What is abundantly clear from the current 'portal moment' in higher education, much change is needed at multiple levels. Importantly in thinking about engineering pedagogy it is going to require more than individual staff - or even staff collaborating as we have in this paper - in individual classrooms on isolated journeys (McMillan, 2017). It is going to require whole institutions to commit to deep change and to ask questions about their relationship to the broader social context in which they are located. Finally, and perhaps most crucially, it requires of us as educators

"to be willing to step back from preconceived ideas of the academic project and where appropriate, acknowledge our own complicity in the decisions that are made that shape the learning of our students. It requires in other words, a change from within, and from [our] context in the Global South, this means a challenging of the structures where decisions are made that reinforce the education of technically excellent but socially and politically dislocated and disinterested student-citizens" (McMillan, 2017:12).

\section{REFERENCES}

Banks, D. \& Lachney, M. (2017). Engineered violence: Confronting the problems of neutrality and violence in engineering. International Journal of Engineering, Social Justice, and Peace, $5,1-12$.

Boud, D. \& Walker, D. (1998). Promoting reflection in professional courses: the challenge of courses. Studies in Higher Education, 23(2), 191-206.

\footnotetext{
${ }^{9}$ See www.globalcitizen.uct.ac.za for contact details of current course staff.
} 
Dei, G. (2014). Indigenizing the school curriculum: The case of the african university. In G. Emeagwali \& G. J. S. Dei, (Eds.) African indigenous knowledge and the disciplines. Netherlands: Sense Publishers (pp.165-180).

Ahmed, A. K. (2017). \# RhodesMustFall: Decolonization, Praxis and Disruption. Journal of Comparative \& International Higher Education, 9(Fall), 8-13.

Ahmed, A. (2020). \#RhodesMustFall: How a Decolonial Student Movement in the Global South Inspired Epistemic Disobedience at the University of Oxford._African Studies Review, 63(2), 281-303. doi:10.1017/asr.2019.49

Nyamnjoh, F. (2012). 'Potted plants in greenhouses': A critical reflection on the resilience of colonial education in Africa. Journal of Asian and African Studies. 47(2),129-154.

McMillan, J. (2017). "I understand that infrastructure affects people's lives: Deliberative pedagogy and community-engaged learning in a South African engineering curriculum". In T. Shaffer, N.V. Longo \& M. Thomas (Eds.), Deliberative pedagogy and democratic engagement (pp.159-168). East Lansing, MI: Michigan State University Press.

Oliver, S. (2015). Engineering knowledge: An ethnographic analysis of community engagement in the classroom. UCT Honours thesis. Department of Social Anthropology. (Unpublished).

Pillay, S. 2015. Decolonizing the university. Talk given at Azania House, University of Cape Town, April. Http://africasacountry.com/2015/06/decolonizing-the-university/ 